\title{
DEMOCRACIA E SOCIEDADE DE MERCADO: TEXTOS INÉDITOS DE ÉLIE HALÉVY*
}

\author{
Michele Battini
}

\section{I}

Élie Halévy deve ser considerado ainda hoje um dos maiores historiadores do século XX, em primeiro lugar por seus estudos fundamentais sobre a economia política e o utilitarismo, bem como sobre o movimento operário social e comunista.

Ère des tyrannies e a Histoire du socialisme éuropéen são considerados marcos fundamentais da crítica neoliberal da utopia iluminista e do seu êxito no sistema tirânico comunista (Halévy, 1938, pp. 213-5, 1948). A interpretação nesse sentido foi imediatamente proposta por Raymond Aron, na homenagem realizada pela Société Française de Philosophie e publicada (de forma mais ampla) na Revue de Métaphisique et de Morale em 1939; François Furet, Pierre Bouretz e Monique Canto-Sperber limitaram-se a propor novamente em anos mais recentes aquela mesma leitura, inserindo

\footnotetext{
* Tradução de Carlo Alberto Dastoli.
} 
o retrato de Halévy na galeria ideal que, de Montesquieu e Tocqueville, conduz ao próprio Aron (1939) ${ }^{1}$.

O capítulo decisivo dessa linha de interpretação foi justamente a edição póstuma da Histoire du socialisme éuropéen, editada com base - assim afirmaram os organizadores nas anotações e nos apontamentos inéditos dos cursos sobre socialismo que Halévy ministrava na École Libre des Sciences Politiques de Paris. O trabalho foi iniciado por Celestin Bouglé antes da Segunda Guerra Mundial², mas foi interrompido pela morte do organizador e de alguns de seus colaboradores. Quando a guerra terminou, esse trabalho foi retomado e levado a termo por Raymond Aron (1948, pp. 9, 12-3). Inexplicavelmente, porém, Aron não incluiu no volume alguns manuscritos importantes e utilizou, segundo critérios a meu ver discutíveis, anotações autógrafas de Halévy e apontamentos feitos por alunos e ouvintes dos cursos. Em decorrência disso, produziu uma edição 218 em que diversas passagens se mostram diferentes dos textos autógrafos conservados no arquivo.

Há alguns anos resolvi iniciar uma pesquisa na École Normale Superieure de Paris, onde, no arquivo de Halévy, são conservadas as fontes e os esquemas dos capítulos preparados pelo autor para a Histoire. Os "dossiês volumosos" citados por Aron estão catalogados como Papiers Halévy e estão conservados na Bibliothèque des Lettres, onde foram

\footnotetext{
${ }^{1}$ Esse texto foi reeditado, com algumas correções, em Aron (1938), texto que corresponde também a uma nova homenagem pronunciada em 1970 e publicada no mesmo ano (Aron, 1970). A leitura de Aron foi proposta novamente por F. Furet, (1995). Ver também Bouretz (1995).

${ }^{2}$ Entre os papéis de Celestin Bouglé, conservados no Archives Nationales de Paris, há algumas cartas interessantes sobre a construção do texto. Em uma carta de Bouglé a Léon Brunschwigg (10 de agosto de 1938), há uma menção sobre o trabalho do próprio Bouglé "para a redação dos Cours de Halévy"; no dia 24 de agosto de 1938, Aron escreve a Bouglé perguntando sobre "a situação dos trabalhos"; enquanto no dia 30, em outra carta a Bouglé (da qual se depreende que também Mantoux trabalhava nos cursos), Aron enfrenta alguns problemas filológicos das traduções francesas de $O$ manifesto comunista.
} 
depositados em 1963 pela última herdeira da família, Henriette Guy-Löé. O acervo consiste em 33 cartons que contêm anotações de leitura, apontamentos, fichas, citações e planos das aulas ministradas na École Libre de Sciences Politiques a partir de 1902. Os documentos são manuscritos, portanto, podem certamente ser atribuídos ao autor.

Há, por exemplo, uma versão manuscrita e parcial de La théorie platonicienne des sciences, o primeiro ensaio publicado por Halévy ${ }^{3}$. É conservada também a farta documentação utilizada para os volumes sobre a sociedade britânica dos séculos XIX e XX e para seus estudos sobre a economia política clássica, o utilitarismo e a filosofia política libe$\mathrm{ral}^{4}$. Há muitas fichas sobre a história religiosa da Inglaterra e sobre as obras de Locke, Hobbes, Hume, James Mill, John Stuart Mill (Cartons IV, V, VIII, X, XIV, XV, XVI, XVII, $\mathrm{XVIII),} \mathrm{enquanto} \mathrm{outros} \mathrm{papéis} \mathrm{estão} \mathrm{rubricados} \mathrm{com} \mathrm{a}$ frase "Notes pour le livre sur Bentham" (Carton XXV).

Muitos documentos sobre o movimento operário britânico se encontram nos Cartons relativos à história britânica e ao utilitarismo, mas os papéis que dizem respeito à história do socialismo europeu e à economia política estão conservados quase exclusivamente nos Cartons I, II, V, V (1), VII, IX, XI, XII, XIII.

A análise sistemática desses últimos documentos reserva muitas surpresas. No carton I, por exemplo, é conservado

\footnotetext{
${ }^{3}$ Ver Papiers Haléry, Carton XXVII, "Notes sur Platon", e XXVIII, "Notes sur la théorie platonicienne des sciences". Em dezembro de 2008, foram depositados novos documentos provenientes da maison blanche (a residência de Halévy fora de Paris) e pela herdeira Henriette Guy-Loë. Somente em março de 2010, foi feito um inventário preliminar: o novo depósito compreende o diário de Florence sobre a viagem à União Soviética, dois dossiês denominados "Vocabulaire Révolution de 1848"; documentos sobre o metodismo inglês, os artigos de Halévy sobre os temas da "Histoire du peuple anglais" e os papéis para a edição da correspondência.

${ }^{4}$ Refiro-me aos três volumes de La formation du radicalisme philosophique. "La jeunesse de Bentham 1776-1789"; "L'évolution de la doctrine utilitaire de 1789 à 1814"; e "Le radicalisme philosophique", publicados originalmente a partir de 1901 e reeditados pela Presses Universitaires de France em 1995.
} 
o texto autógrafo integral, que compreende onze folhas de uma aula inaugural que, provavelmente, Halévy utilizou em diversas ocasiões como introdução aos cursos sobre o socialismo. Isso aconteceu pelo menos durante todo o período de 1902 a 1911, como mostram as datas das aulas anotadas na capa do dossiê.

O texto, rico em reflexões sobre a relação entre a economia política do século XVIII e o socialismo, tem o título de "Évolution des doctrines économiques et sociales en Angleterre et en Allemagne dans le seconde moitié du xixe siècle. Principalement du socialisme, principalement en Allemagne" 5 . Trata-se de um documento extraordinário que, inexplicavelmente, ficou inédito: embora seja um dos poucos manuscritos completos deixados por Halévy, nunca foi incluído na edição de 1948, nem naquela de 1974. A escolha editorial, portanto, deformou a representação da relação genealógica entre economia clássica e socialismo, suposta por Halévy.

220 Outra surpresa provém do Carton VII, 4, no qual estão conservados os textos autógrafos das conferências "F. List et l'économie nationale" e o "Historisme allemand" 6 , publicadas em 1948, depois eliminadas na edição de 1974: a comparação entre o manuscrito e o texto publicado comprova que os documentos não foram publicados íntegra e fielmente (a começar pelo título do segundo documento: "Historicisme", no texto autógrafo, e não "Historisme allemand", como no texto publicado). Isso demonstra sobretudo que uma importante conclusão sobre Marx foi literalmente omitida ${ }^{7}$. Também no Carton VI, 2 estão conservados dois textos dedicados

\footnotetext{
${ }_{5}^{5}$ Papiers Halévy, Carton I, "Introduction 1 cours": Janvier 1902, 12 de novembro de 1903, 9 de novembro de 1905, 12 de novembro de 1907, 1909, 7 de novembro de 1911.

${ }^{6}$ Ver Halévy, (1948, pp. 301-15). Na nota de rodapé lê-se: “Leçon redigée par É. Halévy vers 1903", com uma referência também ao Capítulo 1, chapitre i: "La formation des partis socialistes en Europe: $§ 1$. En Allemagne: la socialdémocratie et la réplique de Bismark", p. 163 e ss.

${ }^{7}$ Ver Halévy, (1948, pp. 328-29) e Papiers Haléry, Carton VII, 4: “L’Historicisme”.
} 
a Marx, relativos à teoria do valor e à concepção materialista da história que foram publicados em ambas as edições, porém, com cortes e interpolações ${ }^{8}$.

A descoberta mais embaraçosa, enfim, provém do carton XI, 3. Refiro-me ao texto "La théorie marxiste de la concentration des capitaux", cuja introdução nunca foi publicada na Histoire du socialisme. Assim perdeu-se a possibilidade de compreender que se tratava do texto de uma única conferência sobre o pensamento de Marx o qual, todavia, foi arbitrariamente dividida em duas partes: a primeira foi publicada em duas seções diferentes do item 1, Capítulo II, Primeira Parte da Histoire du socialisme; a segunda no item 5, Capítulo IV, Segunda Parte. Em decorrência disso, deturpou-se o sentido da relação intelectual estabelecida por Halévy entre os críticos socialistas da economia liberal (Sismondi, Pecquer e Saint-Simon) e Karl Marx.

Como mencionei anteriormente, a introdução a esse manuscrito, cujo título é "La théorie marxiste de la concentration des capitaux" ${ }^{9}$, foi totalmente eliminada: suas primeiras nove páginas foram publicadas separadamente, como seção 1 ("Sismondi et la critique pessimiste") e 2 ("Pequer et la critique optimiste"), do item 1 ("Les premiers critiques de l'économie libérale”) do Capítulo II, Primeira Parte, com o título de "Le socialisme en France de 1815 à 1848” (Halévy, 1948, pp. 48-53, 1974, pp. 64-71) . As páginas seguintes, numeradas no manuscrito de dez a quinze, foram publicadas como item 5 (Comparaison entre Marx et Sismondi) do Capítulo IV, Segunda Parte,

\footnotetext{
8 Papiers Halévy, Carton VII, 2: "Le marxisme. La théorie de la valeur". Este texto foi publicado somente a partir da quarta página do manuscrito em Halévy (1948, pp. 99-112, 1974, pp. 133-51). As quatro páginas censuradas foram substituídas por uma nota de redação. Ver também Papiers Halévy, Carton VI, 2: "Le marxisme. La conception materialiste de l'histoire", publicado com alguns cortes feitos na conclusão (duas últimas páginas do manuscrito)em Halévy (1948, pp. 91-8, 1974, pp. 121-31). ${ }^{9}$ Ver Papiers Halévy, Carton XI, 3: "La théorie marxiste de la concentration des capitaux".
} 
com o título La lutte des classes et l'évolution du capitalisme (Halévy, 1948, pp. 122-125; 1974, pp. 165-169).

Outra evidência dos critérios discutíveis seguidos pelos organizadores da Histoire du socialisme européen surge do Carton XI, no qual está conservado outro manuscrito de onze páginas, com o título "i, Agricolture". Neste caso, não se trata de um texto autônomo, mas sim de um texto autógrafo que era parte integrante de: "La théorie marxiste de la concentration des capitaux". O texto "i, Agricolture”, de fato, é a reconstrução do pensamento de Marx sobre a concentração capitalista no setor agrário e uma tentativa de verificar sua validade, como testemunham as referências evidentes à introdução anteriormente mencionada, "La théorie marxiste de la concentration des capitaux". O próprio estado do papel prova isso sem deixar dúvidas: as bordas da última e da primeira página dos dois textos coincidem.

Após separar materialmente as duas partes, os organi222 zadores publicaram a primeira nas duas seções distintas que descrevi acima, deslocando a segunda ("i, Agricolture") para o Capítulo II, Parte IV, cujo título é "Le socialisme et l'évolution économique” (Halévy, 1948, pp. 201-14; 1974, pp. 27593). Ao término dessa operação, os organizadores deixaram as duas partes em duas pastas diferentes do arquivo. Enfim, também a terceira seção do texto sobre a teoria marxista da concentração capitalista, com o título "ii, Industrie", foi depositada em um terceiro dossiê.

Esse último texto ("ii, Industrie") é um manuscrito de dez páginas, numeradas segundo uma sequência que continua exatamente aquela do manuscrito sobre a agricultura (de 12 a 21): a página 12 é a última do texto sobre a agricultura, que foi claramente reduzido pela metade, como demonstra uma prova elementar: suas bordas coincidem com aquelas da última página de "i, Agricolture" (o manuscrito foi também publicado à parte, como Item 2 do Capítulo II da Parte IV do livro) (Halévy, 1948, pp. 214 e ss., 1974, pp. 294 e ss.). 
II

"Le marxisme: la conception materialiste de l'histoire" é o título do texto autógrafo publicado na Histoire du socialisme com a omissão inexplicável das duas últimas páginas. Em substituição às páginas originais, na edição de 1948, no último parágrafo do trecho final do capítulo, lê-se:

Em resumo: uma evolução dialética que indica a atividade do homem como finalidade do progresso e, por sua causa, a própria atividade do homem, sob seu aspecto concreto e material: assim pode ser definido o marxismo entendido como filosofia da história (Halévy, 1948, p. 98) ${ }^{10}$.

Mas no manuscrito lê-se também um trecho que foi apagado:

Vê-se, portanto, a diferença com relação ao historicismo de Roscher, o qual, depois de ter começado pela economia política, tentou completá-la com uma filosofia integral da história. O homem econômico é uma abstração e uma ficção do espírito, enquanto o homem real, concreto, é um ser não apenas econômico, mas também jurídico, religioso, moral. Há uma ação e uma reação de todas as partes de sua natureza, que reagem umas sobre as outras ${ }^{11}$.

\footnotetext{
${ }^{10}$ No original, lê-se"Bref, une évolution dialectique, qui assigne, pour fin au progrès, l'activité humaine, et pour cause du progrès, l'activité humaine, sous son aspect concret et comme matériel: ainsi peut se définir le marxisme considéré comme philosophie l'histoire". Na versão editada, além das duas páginas conclusivas, falta também a primeira página (na qual Halévy admite não ter consultado a Kritik der nach Hegelschen Philosophie, publicada por Riazanov em Moscou em 1932). Também o manuscrito dedicado "Le marxisme: la théorie de la valeur" (Carton VI, 2) foi publicado somente a partir da quarta página (Halévy, 1948, pp. 98-112; 1974, pp. 134-41).

${ }^{11}$ Papiers Halévy, Carton VI, 2 "Le marxisme: la conception materialiste de l'histoire", p. 3: "On voit la différence avec l'historisme de Roscher. Roscher, parti de l'économie politique, visa à la compléter par la philosophie intégrale de l'histoire. L'homme économique est une abstraction et une fiction de l'esprit: l'homme réel, concret, est un être non seulement économique, mais juridique, religieux et moral. Il y a action et réaction constante de toutes les parties de sa nature les uns sur les autres".
} 
No manuscrito, portanto, Halévy destaca uma diferença decisiva entre os socialistas estatalistas e Marx (os quais Aron, porém, teria identificado) e discute a contradição que, segundo Marx, caracteriza a sociedade de mercado: o conflito entre a organização racional da produção fabril e o mercado sem regras (além do conflito interno ao sistema fabril, entre o capitalista e o trabalhador assalariado). Sob esse aspecto, o capitalismo certamente constitui para Marx um modo de produção despótico, mas, ao mesmo tempo, revolucionário, que destrói e reconstrói continuamente o próprio equilíbrio interno: Halévy enfatiza como Marx sempre sustentou a existência de impulsos que tendem a substituir, dentro do próprio sistema capitalista, o mercado autorregulado por novas formas de regulação, enquanto a média e pequena propriedade é substituída pela grande concentração, particularmente na indústria. Sua conclusão é clara: "Portanto, é um fato que, no século XIX, as [forças?] econômicas exerceram uma ação pre224 dominante no caminho da história e que, consequentemente, para esta época determinada, o materialismo histórico oferece um caráter de verdade relativa" ${ }^{12}$.

A seção introdutória sobre as fontes utilizadas por Marx (as obras de Sismondi e de Pecqueur, por exemplo) foi publicada parcialmente como item avulso do capítulo dedicado ao socialismo anterior a 1848. Contudo ela constitui, ao contrário, a premissa decisiva da reflexão de Halévy sobre o pensamento de Marx $^{13}$, que realça a distância deste autor do modelo hierárquico saint-simoniano:

\footnotetext{
${ }^{12}$ Papiers Halévy, Carton VI, 2, "Le marxisme: la conception materialiste de l'histoire", p. 5: "C'est bien un fait que, au XIX ${ }^{\text {eme }}$ siècle les [palavra incompreensível] économiques ont exercé une action preponderante sur la marche de l'histoire; et que, par suite, pour cette époque determiné, le materialisme historique offre un caractère de verité rélative".

${ }^{13}$ Papiers Halévy, Carton XI, 3, "La théorie marxiste de la concentration des capitaux". "i, Sismondi et Pecqueur". "ii, Karl Marx".
} 
[...] as fontes são francesas: depois das origens alemãs (Hegel) e inglesas (Ricardo), nós reconhecemos as origens francesas: Sismondi e Pecquer, pois Marx foi essencialmente um leitor e assimilador sistemático, e portanto é interessante ver como, graças ao seu poder de análise e de assimilação, ele se apropria das teorias alheias (Halévy, 1948, pp. 48-54; 1974, pp. 64-72) ${ }^{14}$.

A segunda seção do manuscrito, contudo, foi impressa na parte da Histoire e é dedicada a "Marx et le marxisme", omitindo, também nesse caso, o início: "Marx se apropria da teoria pessimista de Sismondi e da teoria otimista de Pecquer sobre a concentração capitalista para fundi-las em um sistema único e original" 15 .

A segunda parte da conferência está armazenada hoje numa pasta diferente daquela em que a primeira foi depositada ${ }^{16}$ e, apesar das condições precárias de con-

\footnotetext{
${ }^{14}$ A parte da introdução "censurada" diz assim: "Nous l'étudions (a teoria marxista, n.d.r.) en elle même et dans ses sources. Cette étude de ces sources aura deux avantages. Les sources sont françaises: après les origines allemandes (Hegel) et anglaises (Ricardo) de la pensée de Marx, nous ne connaîtrons les origines françaises: Sismondi et Pecqueur. Marx est essentiellement un lecteur, un assimilateur systematique; interessant de voir comment, par son pouvoir d'analyse et d'elaborat(ion), il fait siennes, il assimile les théories d'autrui" (Papiers Halévy, Carton XI, 3, "Sismondi et Pecqueur", p. 1). A parte seguinte (páginas 1 a 9 do manuscrito) corresponde fielmente ao texto impresso.

15 "Karl Marx s'empare de la théorie pessimiste de Sismondi et de la théorie optimiste de Pecqueur sur la concentration des capitaux: il les fonds en un système unique et original" (Papiers Halévy, Carton XI, 3, "La théorie marxiste des capitaux", "ii, K. Marx", pp. 9-15, impresso com o título "Comparaison entre Marx et Sismondi ; Apréciation du marxisme", no Capítulo iv, "La lutte des classes et l'evolution du capitalisme", da segunda parte da Histoire du socialisme, (Halévy, 1948, pp. 122-6; 1974, 165-9).

${ }^{16}$ Papiers Halévy, Carton XI, 1, "i. Agriculture”. Esse texto, com algumas interpolações, é substancialmente aquele publicado em Halévy (1948, p. 200 e ss.). Mas há algumas diferenças significativas: o início do manuscrito, por exemplo, foi omitido: "Pourquoi, d'abord, la loi de l'accumulation, de la concentration des capitaux, ne s'apliquerait-elle à l'agriculture comme à l'industrie? Marx le pense et le spectacle de l'évolution de la propriété foncière Angleterre est faite pour lui inspirer cette maniere de voir". ("Por que, em primeiro lugar, a lei da acumulação, da concentração capitalista, não seria aplicável à agricultura como é aplicada à indústria? Marx pensa assim e o espetáculo da evolução da propriedade fundiária na Inglaterra é feita para inspirar-lhe essa maneira de ver").
} 
servação do manuscrito, é fácil comprovar que a edição impressa apresenta diferenças evidentes em relação ao texto autógrafo.

Na edição impressa, por exemplo, é fortemente realçada a diferença entre o setor primário da agricultura e a indústria: o processo de concentração provoca na indústria fenômenos como a intensificação do trabalho, o aumento da exploração, o fortalecimento das práticas disciplinares e de vigilância; na agricultura, porém, ele torna o disciplinamento dos trabalhadores muito mais difícil devido à dispersão organizacional do trabalho e também às formas de especialização, que são mais difíceis de serem realizadas, ao passo que na indústria progridem de modo extraordinário, determinando o aumento da produção graças às máquinas e às operações em série.

$\mathrm{Na}$ indústria, a demanda de mercado constitui um forte estímulo que gera ulteriores fenômenos de concen226 tração, enquanto na agricultura se registram resistências que acabam fortalecendo a pequena e média propriedade; então, daí poder-se-ia deduzir que no setor agrário o papel social do proletariado é desempenhado pelos pequenos agricultores, embora o pequeno proprietário rural não possa ser assimilado ao proletário. A conclusão, no texto editado e organizado por Aron, é que "a lei (marxista) da acumulação, da concentração capitalista, não se aplica à agricultura da mesma forma que à indústria" (Halévy, 1948, p. 205) ${ }^{17}$. O texto do manuscrito, contudo, diz:

Mas, como o número dos proprietários diminui, a quantidade das explorações dos quais é extraída uma renda não se modifica, e não se pode sustentar que haja uma modificação

\footnotetext{
17 “[...] la loi (marxiste) de l'accumulation, de la concentration des capitaux, ne s'aplique-elle pas a l'agriculture comme a l'industrie".
} 
no caráter da exploração: esta é condição essencial para que seja aplicada a lei marxista da acumulação capitalista ${ }^{18}$.

A conclusão do manuscrito é explícita: "A diferença entre cidade e campo significa (que há) uma distinção entre determinados setores da atividade humana (o setor industrial), nos quais a lei da concentração encontra aplicação e outros (o setor agrário) nos quais ela não se aplica ou se aplica mal"19.

Ao mesmo tempo, Halévy afirma que a conservação e até mesmo o desenvolvimento da pequena e média propriedade não autorizam a recusa da análise marxista, porque os investimentos na agricultura europeia, a partir da segunda metade do século XIX, determinaram o aumento das rendas e, portanto, tiveram o efeito de favorecer a concentração das riquezas (além do aumento da pequena e média propriedade agrária). Assim, o fenômeno da concentração das riquezas confirma parcialmente a análise de Marx.

Na última parte do século XVIII, o processo de apropriação privada das terras das comunidades e o surgimento do individualismo agrário tinham favorecido a concentração das riquezas no âmbito da propriedade rural; nas décadas seguintes, na França, assistira-se a um processo oposto quando os decretos revolucionários tinham favorecido a redistribuição, a pequenos e médios proprietários, das terras confiscadas ao clero e aos émigrés.

\footnotetext{
${ }^{18}$ Papiers Halévy, Carton XI, 1, "i, Agriculture”, p. 3: "Mais, le nombre des proprietaires diminuant, le nombre des exploitation sur les quelles prelévent un revenu n'est pas changé: on ne saurait dire qu'il y a une modification dans le caractère de l'exploitation, ce qui justement est une condition essentielle pour que s'aplique la loi marxiste de l'accumulation des capitaux".

${ }^{19}$ Papiers Halévy, Carton XI, 1, "i, Agriculture", p. 12: "La distinction de la ville et de la campagne signifie la distinction de certaines branches de l'activité humaine (industrielles), où la loi de la concentration trouve son aplication, et d'autres branches (agricoles), où elle ne s'aplique pas, ou s'aplique mal".
} 
Durante o século XIX, as pequenas propriedades muitas vezes tinham voltado sob o controle dos grandes proprietários e a mesma tendência verificara-se em outras partes da Europa, confirmando que "a agricultura deve passar continuamente da concentração à fragmentação, e inversamente, enquanto subsistir a organização da sociedade burguesa" ${ }^{20}$. A oscilação entre concentração e fragmentação não desmente a hipótese de Marx, mas impõe uma leitura diferente daquela que Kautsky tinha proposto: os pequenos e os médios proprietários não desaparecem (e não podem sequer ser considerados uma camada social equivalente àquilo que na indústria é o proletariado), porém sofrem os efeitos da mecanização do trabalho, da introdução das máquinas na produção. Portanto, não é possível aplicar o esquema da polarização social, porque é incontestável que a percentagem dos assalariados não prevalece sobre os

${ }^{20}$ Papiers Halévy, Carton XI, 1, “i, Agriculture”, p. 6: “[...] l'agriculture doit passer indéfiniment de la concentration à l'émiettement, et inversement, tant que subsistera l'organisation de la société bourgeoise”. Halévy, na p. 7 deste documento, resume nestes termos uma tese de Kautsky: "Que acontece então? A era do capitalismo na agricultura começa com a expropriação dos pequenos proprietários. Estes, então, emigram para cidades onde a grande indústria exige seus braços. Sucessivamente, porém, chega um momento crítico para as grandes explorações rurais: aumentando o terreno explorado, eles se privam de braços para cultivá-los e as próprias necessidades das grandes cultivações induzem, então, ao ressurgimento da pequena propriedade. Em resumo, não há contradição entre a persistência da pequena propriedade fundiária e a lei da concentração capitalista. Um proprietário muito pequeno é um proletário agrário”. No original: "Que se passe t-il donc? L'ère capitaliste commence en agriculture par l'expropriations des petits proprietaires. Ceux-ci émigrent alors vers la ville, où la grande industrie réclame des bras. Mais alors un moment critique survient pour la grande exploitation rurale: en agrandissant le domaine exploité, elle se prive des bras pour le cultiver. Les besoins mêmes de la grande culture créent de lors une renaissance de la pétite propriéte. Bref, il n’y a pas contradiction entre la persistance de la pétite propriéte foncière et la loi de la concentration capitaliste. Le très pétit proprietaire foncier est un prolétaire agricole". Sobre a tese, apresentada em 1899 por K. Kautsky no Agrarfrage, ver Kautsky (1959, pp. LXXI, 192-3). Ver também Panaccione (1974, pp. 5-36); sobre a temática da concentração econômica, a obra fundamental da cultura social-democrata marxista alemã foi, como é sabido, a de Hilferding (1961). 
pequenos proprietários, sobre os arrendatários e sobre os meeiros, mas a análise marxista da concentração de riquezas permanece válida.

Halévy evidencia toda a importância da reflexão de Bernstein. Se a concentração das riquezas leva a um aumento da renda fundiária, os socialistas deveriam concentrar-se na luta contra a renda, favorecendo a formação de uma classe de pequenos proprietários, para organizá-los na cooperação contra os grandes proprietários e para defender arrendatários e meeiros, incentivando-os a fazer uma aliança com os trabalhadores rurais ${ }^{21}$. Os limites da "lei da concentração capitalista" na agricultura não colocam em discussão a hipótese que Marx propôs para a superação das relações de produção capitalistas, mas impõem sua redefinição.

A conclusão é reforçada pela consideração de que a lei da tendência à concentração capitalista parece, todavia, plenamente confirmada no âmbito fundamental do sistema capitalista moderno, o da indústria. Na parte não publicada do texto sobre a concentração, de fato, lê-se:

Parece que a aplicação da lei da concentração capitalista à indústria propriamente dita implique menos restrições, pois foi extraída da observação dos fenômenos da evolução industrial na Europa e, em particular, na Inglaterra, principalmente por parte de Sismondi, depois por parte de Marx. Aquela "lei" continua operando: toda vez que se vê na cidade uma loja de departamentos destruir, por meio de uma concorrência desleal, os pequenos comerciantes, forçando-os a emigrar ou a se tornar assalariados da grande empresa; e toda vez que se ouve falar de monopolização da indústria (petróleo ou aço), num

${ }^{21}$ Papiers Halévy, Carton XI, 1, “i, Agriculture”, p. 9. 
país inteiro ou no mundo inteiro, por parte de empresas gigantescas, temos outras provas tangíveis e palpáveis da verdade da teoria de $\operatorname{Marx}^{22}$.

No comércio ou na indústria, a exigência das grandes empresas de integrar no próprio ciclo de produção as pequenas empresas, ou a tendência das lojas de departamentos a englobar também os pequenos centros de distribuição, poderiam soar como uma negação do fenômeno da concentração ${ }^{23}$, enquanto na realidade, esse fenômeno se verifica - observa Halévy - não apenas através da formação de cartéis ou trustes, mas sim também nas formas da associação dos pequenos capitalistas, da criação das sociedades anônimas e da separação entre capital e direção da empresa. Trata-se de entender se esses processos aumentam ou diminuem o número dos indivíduos interessados na preservação do sistema, ou 230 em sua destruição.

A categoria de propriedade, moldada historicamente na noção de propriedade da terra, com seus direitos de uso e de abuso, sofre uma modificação e, desde o final do sécu-

\footnotetext{
${ }^{22}$ Papiers Halévy, Carton XI, 1, “ii, Industrie”, p. 12 : "Il semble que l'aplication de la loi de la concentration capitaliste à l'industrie proprement dite comporte moins de restriction: c'est à l'observation des phénomènes de l'évolution industrielle en Europe, et particulièrment en Angleterre, qu'elle à été emprunté, d'abord par Sismondi, ensuite par Marx. Elle à continué a se vérifier. Chaque fois que, dans une ville, nous voyons un grand magazin détruire, par sa concurrence triomphante, tout les petits commerçants, obligés soit à émigrer, soit à dévenir salariés de la grande entreprise; chaque fois que nous entendons parler de la monopolisation de toute une industrie - petrol ou acier - dans un pays tout entier, presque dans le monde entier, par des entreprises gigantesques, nous avons là comme autant de preuves tangibles, palpables, de la verité de la théorie marxiste". O início do texto sobre a indústria corresponde à segunda parte da seção anterior ("Agriculture") da reflexão sobre a concentração: a parte foi separada, ao se dividir a página $12 \mathrm{em}$ dois trechos, e foi publicada separadamente.

${ }^{23}$ Papiers Haléry, Carton XI, 1, "ii, Industrie”, p. 13.
} 
lo XIX, transforma-se numa categoria e numa função separada do controle (Halévy, 1948, pp. 215-8). Em uma página do manuscrito omitida na edição impressa, Halévy insiste também no efeito de moderação dos conflitos sociais determinado, paradoxalmente, pela organização operária e pelo desenvolvimento do sindicato:

A concentração dos capitalistas é acompanhada, no mundo moderno, por um movimento inverso de concentração de forças operárias. Desses processos é possível deduzir, sem dúvida, a prova que demonstra como a concentração industrial avilta a condição operária, de acordo com o que se afirma na teoria marxista, pois ela torna mais fácil a vigilância dos trabalhadores [...]. Mas a esses dados é possível contrapor outros, provavelmente mais significativos, que Sismondi, apesar do seu pessimismo, já evidenciara.

Em todos os lugares onde a grande indústria se estabeleceu, os trabalhadores ganharam a liberdade de organização [...]. Nos Estados Unidos, os chefes do movimento socialista estão bem longe de hostilizar o desenvolvimento dos grandes trustes e muitos deles hesitam diante da perspectiva de incentivar o início de uma legislação antitruste. Não parece verdade, então, que o desenvolvimento da concentração capitalista signifique para eles um agravamento da miséria [...], e é também notável o número de socialistas que, consciente ou inconscientemente, abandonaram o ponto de vista marxista. Não se trata mais de anunciar a catástrofe para uma data mais ou menos próxima [...], mas imaginar, desde já, os instrumentos mais apropriados para atingir e diminuir o lucro no seio da sociedade capitalista. 
Sindicalismo, cooperação, intervenção do Estado: estas são as formas de socialismo parcial ${ }^{24}$.

O sentido da definição "socialismo parcial" parece-me evidente à luz da análise dos textos anteriores: o processo de concentração é confirmado no setor fundamental da indústria, mas o fenômeno concomitante da concentração sindical produz efeitos de moderação do conflito de classe, mantendo totalmente aberta, contudo, a perspectiva de transformação da economia capitalista, cujo êxito depende não só da evolução estrutural, mas também da ação política dos socialistas: a estrutura econômica abre espaço às forças sociais e à sua ação subjetiva, contudo deixa incertos os resultados de um confronto histórico que pode desembocar no socialismo. Isso, contudo, só ocorrerá à medida que o sindicato e as cooperativas forem capazes de construir um mercado socialmente regulado e a legislação souber 232 garantir os direitos sociais no contexto de uma democracia industrial autêntica.

\footnotetext{
${ }^{24}$ Papiers Halévy, Carton VI, 2, "ii, Industrie", p. 20: "La concentration des capitaux s'accompagne, dans le monde moderne, d'un mouvement inverse de concentration des forces ouvrières. On peut sans doute arguer de bien ces faits pour prouver que la concentration industrielle àvilit la condition de l'ouvrier, conformement à la lecture de la théorie marxiste: elle rend plus facile la surveillance des ouvriers. [...] Mais a ces faits ont peut oposer d'autres faits, probablement plus significatifs: Sismondi, malgré son pessimisme, l'avait dejà remarqué. Partout ou la grande industrie s'est établie, les ouvriers on obtenu la lib.[erté] de coalition [...]. En Amerique, les chefs du mouvement socialiste sont loins d'être hostiles au dévelopement des grands trusts et plusieurs hésitent à encourager le mouv.[ement] de législation contre les trusts. Il ne semble donc pas que le dévelopement de la concentration capitaliste signifie pour eux une aggravation de la miserè $[\ldots]$. Et le nombre des socialistes est grand, qui, consciemment ou inconsciemment, des à présent, a abandonné le point de vue marxiste. Il ne s'agit plus d'annoncer pour une date, plus ou moins prochaine, le cathaclysme. [...] Il s'agit, pour eux, des à present, d'imaginer des ingredients propres à suprimer, ou à diminuer, le profit au sein d'une société capitaliste encore. Syndicalisme, coopération, étatisme: telles sont le forms de ce socialisme partiel”.
} 


\section{III}

A questão da concentração industrial, agrária e financeira parece decisiva para verificar a validade das teses socialistas. Halévy distingue, para tanto, planos diferentes: a morfologia da propriedade, a intensidade dos investimentos, a modernização da organização da produção e do trabalho e a formação dos novos grandes sindicatos da indústria (unions). No sistema econômico capitalista, Estado e instituições sociais do movimento operário são características decisivas da estrutura.

As consequências que Halévy tira disso vão em direção diferente daquelas que Émile Durkheim extraíra nas suas lições sobre o socialismo ministradas na Universidade de Bordeaux no outono-inverno de 1895-1896, mas é interessante notar que o ponto de partida da reflexão de ambos é o mesmo: a teoria saint-simoniana, interpretada como o paradigma do socialismo industrial moderno (embora a avaliação teórica do estatalismo proposta por Durkheim, contrariamente àquela de Halévy, seja absolutamente positiva) (Mauss, 1928, p. XIV). A sociedade industrial hierárquica, ou seja, o sistema industrial dirigido pelas elites da tecnocracia, pelos banqueiros, pelos produtores, corresponde, segundo Durkheim, às necessidades objetivas impostas pela concentração industrial e financeira: as necessidades de coordenar organicamente as funções da economia com a administração do Estado. O núcleo do socialismo, para Durkheim, reduz-se portanto a uma "força objetiva" e irreprimível para integrar grande indústria e Estado, sem modificar a estrutura da propriedade: capitalismo de Estado, corporações, função dos bancos - exatamente como profetizara Saint-Simon.

Halévy olhou, porém, para além do Canal da Mancha, para os socialistas fabianos, para sua concepção da cooperação; para o federalismo fiscal, financeiro e cooperativista proposto por Cole (1967, pp. 9, 16 e ss., 80 e ss., 99 e ss., 270 e ss.) como soluções correspondentes às exigências da economia moderna, bem como para as interpretações 
modernas da instância da justiça social, com base no direito natural e no princípio utilitarista do interesse da maioria. O socialismo, em resumo, propõe novamente a questão da justiça e da democracia econômica (Venturi, 1962, pp. 8257; Lichtheim, 1969, p. 219; Hobsbawm, 1978, p.13).

Os críticos de Marx - Adler (1878, pp.78, 163-5), Wolf (1892, pp. 132, 181-210), Herkner (1891, pp. 14, 93 e ss. $)^{25}$ - podem ser refutados justamente com base nas teorias dos fabianos e do seu "brilhante aluno alemão", Bernstein ${ }^{26}$.

Em 1896, na Neue Zeit, Bernstein publicara o texto mais importante de sua fundamental crítica à ortodoxia teórica social-democrata e, logo depois, desenvolveu as implicações políticas dessa crítica no célebre ensaio sobre os "pressupostos do socialismo" (Bernstein, 1969) ${ }^{27}$, sustentando que o movimento operário deveria explorar a força dos sindicatos e do partido para conquistar relações de força na sociedade e para desenvolver uma ação reformadora, construindo 234 uma aliança política com os liberais no Reichstag.

A alavanca do progresso social deveria ser identificada na democracia econômica fundada sobre a ação do sindicato e da cooperação, sem esperar a catástrofe improvável do capitalismo: a época do messianismo social tinha que terminar (Bernstein, 1969).

Bernstein contrapôs à ortodoxia de Kautsky (1899, p. $181)^{28}$ uma concepção inovadora da democracia industrial

\footnotetext{
${ }^{25}$ Ver de seu mestre Brentano (1890, pp. 7 e ss.).

${ }^{26}$ Halévy cita principalmente os ensaios mais inovadores escritos por Bernstein na primeira metade dos anos de 1890: Bernstein (1893, pp. 539 e ss., 1891, p. 605).

${ }^{27}$ Leituras reducionistas do texto em termos de "empirismo grosseiro" foram propostas por Panaccione (1974, pp.15 e ss.) e por Gustafsson (1974, pp. 150 e ss.). P. Angel (1961), porém, propôs uma interpretação mais sutil, lembrando que também Marx tinha constatado o fenômeno do aumento da classe média, conforme Marx (1970, p. 628). Sobre a experiência política de Bernstein durante a estadia no Reino Unido, ver D'Elia (1999, pp. 29-55).

${ }^{28}$ Sobre esse ponto, ver a introdução de Procacci a Kautsky (1959), assim como Holzhener (1972). Obrigatórios são os trabalhos de Salvadori (1976, pp. 21 e ss.; 1978, p. 285).
} 
inspirada no exemplo das trade-unions britânicas e capaz de uma iniciativa política que valorizasse a ação parlamentar, asseguradora e cooperativa (mesmo tirando disso conclusões opostas no plano estratégico, também a esquerda socialista e sindicalista revolucionária, como é sabido, compartilhou a análise de Bernstein ${ }^{29}$ ).

Halévy (1948, pp. 344-50) dedicou a Bernstein, portanto, um longo manuscrito - este também publicado só em parte e com as interpolações habituais na Histoire $d u$ socialisme $^{30}$-, para destacar o papel de Bernstein como teórico da contratação coletiva, da normatização por lei das relações de trabalho e do papel dos seguros mutualísticos, em suma, das instituições fundamentais do Estado social ${ }^{31}$.

\begin{abstract}
Chega, contudo, o momento em que não é mais possível desconhecer a importância do movimento sindical:

Bernstein encarna esse momento da evolução da socialdemocracia alemã. Preste-se atenção, contudo, à sua
\end{abstract}

\footnotetext{
${ }^{29}$ A referência fundamental é naturalmente à Sorel, em particular, ao texto Réflexions sur la violence, cuja herança passou para a esquerda sindicalista e, depois da Primeira Guerra Mundial, para a nova esquerda conselheira (Sorel, 1908, p. 287 e ss.). Para a Neue Linke, ver Lukács (1970) e Korsch (1929, pp. 126 e ss.). Uma reconsideração geral da Bernstein Debatte foi feita por Steinberg (1971, pp. 115-26). ${ }^{30} \mathrm{O}$ texto manuscrito não é interrompido à p. 350 da edição (que, portanto, corresponde à página n. 10 do manuscrito), mas prossegue com mais duas páginas (11 e 12 no manuscrito), que não foram reproduzidas. Os assuntos tratados nessas duas páginas são dedicados a Bernstein e aos Webb e correspondem em larga medida àqueles das páginas 183-184 da edição impressa; a página 13 do texto autógrafo, porém, foi substituída pelas páginas 186-190. O sentido dessas interpolações corresponde a uma certa subestimação da importância que tivera, para Bernstein, a experiência do sindicalismo inglês (que foi valorizada também pelos Webb, cujos organizadores da Histoire, contudo, acentuam as posições imperialistas e os escritos antiliberais (Halévy, 1948, pp. 186-90). Além disso, deve-se realçar que o texto manuscrito, cujo título é "Le syndicalisme", consta, no original, de dezesseis páginas: dez (correspondentes àquelas impressas com o título "Marxisme et syndicalisme" (pp. 344-50) estão conservadas no Carton I, 3; seis, correspondentes ao item "Importance de l'école fabienne", pp. 183-190, porém, estão conservadas no Carton II, 2, com o título "Le syndicalisme, les fabiens".

${ }^{31}$ Papiers Halévy, Carton II, 1, "Le syndicalisme, les fabiens", pp. 10-11; ver Halévy (1948, pp. 184-5).
} 
carreira: convertido em 1872 ao socialismo moderado, aquele de Dühring, de Lanz (?) de Hockberg e depois, em 1878, à teoria marxista da leitura do Antidühring, ele se torna, na Suíça e a partir de 1880, redator-chefe do órgão oficial do partido socialista alemão, o Sozial Demokrat; em 1889 é expulso da Suíça com os outros redatores e vai para Londres, onde descobre o movimento sindical inglês, dentro do qual está surgindo um novo socialismo não marxista. Mais uma vez, para estudar a história do novo sindicalismo, somos reconduzidos da Alemanha à Inglaterra. Desde 1878, com efeito, um novo espírito penetrou nas Trade Unions: vota-se a favor da nacionalização da terra e da jornada de trabalho de oito horas (as duas moções, apresentadas no congresso e inicialmente rechaçadas, são adotadas em seguida [...]). Em 1889, depois da grande greve dos dockers, formam-se os novos sindicatos, que recrutam entre os trabalhadores não qualificados e nas fileiras daqueles que pareceram, até aquele momento, refratários a qualquer organização: trabalhadores dos docks, sazonais e trabalhadores das ferrovias, os quais acentuam assim o caráter socialista do novo sindicalismo (New Unionism).

Esse socialismo sindical encontra os próprios teóricos na escola fabiana, cujos representantes principais são os cônjuges $\mathrm{Webb}^{32}$.

\footnotetext{
${ }^{32}$ Papiers Halévy, Carton II, 1, "Le syndicalisme, les fabiens", pp. 11-12: "Le moment arrive, cependant, ou il ne peut plus meconnaître l'importance du mouvement syndicaliste: Bernstein incarne ce moment de l'évolution du parti socialiste allemand./ Mais que l'on fasse attention à la carrière de Bernstein. Converti en 1872 à un socialisme moderé, au socialisme de Dühring, de Lanz (?), de Hockberg; converti en 1878 à la doctrine marxiste par la lecture de l'AntiDühring, il devient en Suisse, à partir de 1880, le redacteur en chef de l'organe officiel du parti socialiste allemand, le Sozial Democrat; c'est en 1889 qu'il est expulsé de Suisse avec les autres redacteurs et passe à Londres, y decouvre le mouv.[ement] synd.[icaliste] anglais et la naissaince, au sein des syndicats anglais, d'un nouveau socialisme qui n'est pas le marxisme. Une fois de plus, pour étudier l'histoire du nouveau syndicalisme, nous sommes ramenées de l'All[emagne] en Angleterre. / Depuis 1878, un esprit nouveau penétre les trad.(e) Un[ions] anglaises: on vote des motions en faveur de la nationalisation du sol et de la journée de huit heures, [...] presentés
} 
Halévy conduz a origem do novo socialismo de Eduard Bernstein às contribuições do economista escocês Davidson e aos cônjuges Webb.

\author{
Vê-se a diferença da evolução histórica entre a Inglaterra \\ e a Alemanha. Aqui o movimento sindical está diante de \\ um partido socialista com um caráter fortemente político \\ e revolucionário, organizado com base na teoria marxista \\ e hostil à ideia sindical: é necessário, portanto, conseguir \\ penetrar no partido e numa teoria hostil a partir de \\ fora; ao contrário, na Inglaterra, é a ideia socialista que \\ encontra um movimento sindical organizado, sem uma \\ teoria, e caso tivesse uma, desconfiaria do coletivismo \\ revolucionário. Aqui, portanto, é necessário que a \\ ideia socialista consiga penetrar a organização sindical \\ preexistente a ela a partir de fora. Essa penetração é \\ permitida, de alguma forma, pelo grande livro dos Webb \\ sobre a Democracia industrial: título que por si só define o \\ sentido da obra ${ }^{33}$.
}

aux congrès, repoussés d'abord, puis adoptés [...]. En 1889, à la suite de la grande grève des dockers, il se constitue de nouveaux syndicats, recrutés parmi les ouvriers non qualifiés, dans les rangs de ceux qui avaient paru jusque là rebelles à toute organisation: ouvriers des docks, ouvriers saison, ouvriers des chemins de fer: ils accentuent le caractère socialiste du Nouveau Unionisme. Le socialisme syndical trouva ses doctrinaires dans l'École fabienne, dont les principaux représentants son M. et M.me Webb".

${ }^{33}$ Papiers Halévy, Carton II, 1, "Le syndicalisme, les fabiens", p. 13: "On vôt la différence de l'évolution historique en Angl[eterre] et en All[emagne]. En All[emagne] le mouv[ement] synd[icaliste] trouve en face de lui un parti socialiste, à caractère strictement révolutionnaire ou politique, org[anisé] sur la base de la doct[rine] marx[iste], hostile à l'idée syndicale: il faut réussire à penetrer, comme du dehors, un parti et une doctrine hostile. En Angl[eterre], au contraire, l'idée socialiste recontre un mouvement syndical organisé, sans doctrine et, si il avait une doctrine, assez défiant à l'égard du collectiv[isme] révolut[ionnaire]]. Ici il faut que l'idée socialiste reussisse à pénetreer, comme de dehors, cette org[anisation] unioniste dejà existante. C'est par le grand livre des Webbs sur la Démocratie Industrielle que cette pénetration est en quelque sorte datée. Le titre de l'ouvrage en définit le sens". 
Contudo, na obra dos Webb e de Bernstein, Halévy reconhece a marca autêntica "de la méthode de Marx", principalmente na escolha de combater a escola econômica marginalista austríaca, que contestara a teoria da relação entre valor de troca da mercadoria e a quantidade de trabalho incorporada nela, sustentada tanto por Adam Smith como por Karl Marx. "A solução austríaca" nega a contradição entre valor de troca e valor de uso: a exigência do consumidor e a escassez de um bem determinam, segundo os marginalistas, o valor efetivo da mercadoria. A utilidade final, ou marginal, estabelece o preço da mercadoria: o viajante que, no deserto, dispõe apenas de cinco litros de água considera só a utilidade do último, aquela que estabelece o valor dos outros quatro ${ }^{34}$.

Jevons, Menger e Walras sustentaram que o lucro é determinado na troca entre o valor de um bem presente e o valor menor de um bem futuro da mesma natureza e 238 quantidade do bem presente; o lucro, então, não é mais o resultado final da mais-valia produzida pelo trabalhador e confiscada pelo proprietário dos meios de produção, mas deve ser considerado a recompensa recebida pelo empreendedor por ter adiantado os capitais necessários para o início da empresa, para a organização técnica da produção e para o salário do trabalhador. Marx contestara as conclusões de Bentham e Ricardo, entretanto Jevons, Walras e Menger criticaram Marx: ou seja, a economia política liberal e a crítica da economia política lutaram entre si durante um século, desde quando, em 1817, Sismondi e, em 1867, Marx superaram Ricardo e Say; depois,

\footnotetext{
${ }^{34}$ Papiers Halévy, Carton XI, 2, "La théorie autrichienne de la valeur". Trata-se de outro texto inédito no qual Halévy leva em consideração a primeira geração dos economistas da escola marginalista e privilegia o ramo austríaco, que a partir de Carl Menger, atuante de 1870 a 1890, conduz aos alunos Friedrich von Wieser e Eugen Böhm-Bawerk, ambos atuantes até à metade dos anos de 1920. Ver Menger, (1934, pp. 92-192). Menger, porém, nunca usou o termo "utilidade marginal", que foi introduzido por Wieser (1889, p. 60 e ss.).
} 
a economia liberal marginalista responder com sucesso ao socialismo. "A verdade”, segundo Halévy, não se esgotava em nenhuma das duas posições teóricas e, aliás, entre os dois princípios de distribuição das riquezas, troca e necessidade, seria necessário chegar à conciliação.

\section{IV}

Halévy não considera que o socialismo fora rejeitado teoricamente $^{35}$, mas seu destino parece-lhe confiado ao desenvolvimento espontâneo da cooperação ${ }^{36}$. Halévy, a esse respeito, lembra que John Stuart Mill valorizara as cooperativas de consumo como a de Rochdale, fundada em 1844, na perspectiva de uma economia coletivista, e que Marx considerara as cooperativas de produção (mas não aquelas de consumo) como um exemplo de estratégia de superação do capitalismo, mostrando-se possibilista a respeito do desenvolvimento de uma democracia industrial da cooperação e da ação sindical ${ }^{37}$. A única solução para a construção de um mercado socialista, portanto, parece consistir no entrelaçamento entre a cooperação, a ação do sindicato e a legislação social.

Da união e da constante aproximação dessas duas instituições já existentes, a cooperativa de consumo e

\footnotetext{
${ }^{35}$ Papiers Halévy, Carton XI, 2, "La théorie autrichienne de la valeur", pp. 2-3.

${ }^{36}$ Papiers Haléry, Carton IX, 4, "Le cooperatisme", pp. 2-17: "Le syndicalisme, tel que nous l'avons défini, augmente le salaire au détriment du profit: il ne suprime pas le profit: il ne constitue donc pas un socialisme intégral. Pour aboutir au collectivisme, ou au communisme, il doit être completé par le cooperatisme, ou par l'étatisme: en d'autres termes, l'action des organisations syndicales, en vue de relever les salaires, doit être completée par le dévelopement spontanée, au sein de la société actuelle, soit des cooperations, soit des services d'État. Plusieurs socialistes, défiants à l'égard des reformes sociales que pouvrait engager l'État bourgeois, préferent compter, pour la réalisation d'une société collectiviste, sur le dévelop[pement] spontané, au sein de la société actuelle, des cooperatives. Tel Bernstein". Só algumas partes do texto são reconhecíveis no item "Le socialisme et la cooperation" de Halévy (1948, pp. 218-24).

${ }^{37}$ Papiers Halévy, Carton IX, 4, "Le cooperatisme", pp. 8-9.
} 
o sindicato, os novos socialistas esperam a realização progressiva e espontânea do regime socialista. Os membros da cooperação são como os cidadãos "de um Estado no Estado" (Roscher, Webb) e de uma "república social" que regulam, com método e de acordo com as necessidades do consumo, a produção industrial integral. Ao mesmo tempo, os membros do sindicato são os funcionários da cooperação para um ramo definido da produção, ao passo que o conjunto dos cidadãos organizados em sindicatos constituem o poder administrativo da cidade coletivista (porque todo sindicato faz ouvir as reivindicações profissionais e econômicas dos próprios membros, através dos seus representantes), enfim, o conjunto dos cidadãos, agrupados numa vasta cooperativa de consumo ou na federação das cooperativas, constituirá o poder executivo, elemento decisivo para o progresso democrático ${ }^{38}$.

\section{Em 1906, Halévy voltaria ao problema da cooperação:}

Todos os teóricos da escola liberal ortodoxa propendem mais ou menos abertamente para a primeira alternativa (o princípio de troca, n.d.r.); todos os teóricos do socialismo, ao contrário, tendem a interpretar os fenômenos econômicos como processos de distribuição das riquezas [...]. Não existem, para eles, leis naturais da troca, pelas

\footnotetext{
${ }^{38}$ Papiers Halévy, Carton IX, 4, "Le cooperatisme", p. 14: "De l'union, du rapprochement constant de ces deux institutions dejà existants - la cooperation de consommation et le syndicat - les nouveaux socialistes attendent la réalisation progressive et spontanée du regime socialiste. Les membres de la cooperation sont les membres 'd'un état dans l'état' (Roscher, Webb), 'd'une république sociale', qui règlent méthodiquement, sélon les besoins de la consommation, la production industrielle integrale. Les membres du syndicat sont les employés de la cooperation pour une branche definie de la production. L'ensemble des citoyens, groupés en syndicats, constituent le pouvoir administratif de la cité collectiviste (chaque syndicat faisant entendre, par la voix de ses réprésentants, les revendications économiques ou professionnelles de ses membres). L'ensemble des citoyens, groupés en une vaste coop.[erative] de consommation, ou en une fédération de ces coop., constituera le pouvoir constitutif, l'élément pour le progressement démocratique".
} 
quais os fenômenos econômicos sejam governados universalmente pela eternidade (Halévy, 1906a, pp. 548-9) ${ }^{39}$.

O princípio da livre-troca não pode ser considerado o único modelo das relações de troca, sejam elas econômicas, sociais ou de outra natureza: a impossibilidade de utilizar a unidade de medida do valor na avaliação de cada relação social e dos critérios de ética pública é demonstrada pelo fato de que o equilíbrio dos interesses não corresponde ao critério de justiça. As relações sociais não são apenas relações de troca: a relação entre o capitalista e o assalariado, por exemplo, como relação entre capital inicial, de um lado, e excedente produzido, de outro, não é uma troca paritária, nem o salário constitui o preço pelo qual o valor do trabalho é vendido. "É necessário, portanto, abandonar a teoria segundo a qual o salário é este preço, pelo qual o valor se vende, quando se vende pelo próprio valor". O salário, porém, pode ser definido pelo preço de troca do trabalho, como sustenta Ricardo, somente se aceita-se considerar o trabalho uma mercadoria; esta, porém, normalmente não é paga de acordo com seu valor efetivo, e os assalariados não vendem o trabalho, mas sim a própria força-trabalho, isto é, a soma dos trabalhos realizados, das energias gastas para produzir a mercadoria, dos esforços indispensáveis para manter e reproduzir a força-trabalho, ou seja, a si mesmos, assim como as próprias famílias. Por conseguinte, deve-se destacar que os economistas ortodoxos empobrecem a complexidade das relações de troca numa teoria das relações comerciais. $\mathrm{O}$ contrato de traba-

\footnotetext{
${ }^{39}$ Sobre este ensaio, ver Frobet (2003, p. 61 e ss.): "Plus ou moins ouvertement, tous les théoriciens de l'école dite libérale, ou 'orthodoxe', penchent pour la première alternative; tous les théoriciens du socialisme, au contrarie, penchent pour l'interpretation des phénomènes économiques comme procès de distribution des richesses [...]. Il n'existe pas des lois naturelles de l'échange, par lesquelles soient, universellement et éternellement, gouvernés les phénomènes économiques".
} 
lho não pode ser analisado apenas como uma forma de troca entre partes iguais, porque ele é o produto de relações de força historicamente determinadas; não se trata, portanto, de deixar de lado, absolutamente, a noção de troca, mas de admitir que

[...] o efeito da troca é produzir uma contradição de interesses entre uma classe de ricos ociosos e de trabalhadores miseráveis, uma desarmonia econômica [...]. Sem trair Marx, não se pode dar um passo adiante? (Halévy, 1906a, pp. 546) ${ }^{40}$.

Portanto, segundo Halévy, considerar a relação capital-salário como uma forma de troca é um erro. Isso não deve levar, contudo, à conclusão errada de que a economia de mercado, onde esses contratos são estabelecidos, seja totalmente absurda. Catastrófica, no caso, é a sociedade de mercado idealizada pelos economistas clássicos, ou seja, a ideia de uma 242 sociedade em que não há relação fora do modelo de mercado, em que indivíduos são considerados apenas na qualidade de proprietários e possuidores de mercadorias. A conclusão leva Halévy a liquidar a teoria neoliberal do contrato de trabalho proposta por Böhm-Bawerk, seja na forma da troca entre salário (bem presente) e produto (bem futuro), seja na forma do ganho de um interesse legítimo por parte do capitalista que paga o salário, justificada com o pressuposto do risco por parte do empreendedor.

A produtividade de capital e trabalho e o valor de uma mercadoria, para Böhm-Bawerk, aumentam em função do tempo que intercorre entre a fruição do bem presente (o salário antecipado ao trabalhador para produzir a mercadoria) e a fruição do bem futuro. A mercadoria é "produzida pelo concurso de trabalho e capital: portanto, cabe ao

\footnotetext{
40 “[...] l'échange a pour effet de produire une contradiction d'interêts entre une classe de riches oisifs et de travailleurs miserables, une désharmonie économique [...]. Sans trahir Marx, ne peut - on pas aller encore un pas plus loin?”.
} 
capitalista e aos trabalhadores distribuir entre si os valores, segundo princípios que não implicariam nada de fixo, de estabelecido" (Halévy, 1906a, p. 566) ${ }^{41}$. Essa hipótese não convence Halévy, que se limita a observar que todo tipo de troca é o produto histórico das instituições e das normas jurídicas elaboradas por uma sociedade, como ocorreu também com o mercado autorregulado do século XIX, "um modo artificial de distribuição das riquezas". O mercado autorregulado não é, como sustentam von Mises e Hayek, uma ordem natural, cataláctica, mas sim o resultado de uma escolha política: como qualquer sistema de distribuição das riquezas, ele constitui uma escolha política e "artificial" 42 .

Halévy parte, em suma, de uma tese oposta à dos economistas neo-ortodoxos da escola marginalista. Ele concebe a sociedade não como um jogo de concorrência entre os indivíduos, mas como uma comunidade, na qual todos os indivíduos são titulares da propriedade de um capital social; e nem mesmo o direito de propriedade é uma categoria transcendental, mas sim uma realidade histórica. Portanto, a aspiração capitalista da maximização do lucro ou da renda, bem como as pretensões salariais dos trabalhadores, devem encontrar um limite no consenso coletivo, nas razões sociais da empresa. Aqui, Halévy parece aludir à teoria da propriedade como função social: a reciprocidade que necessariamente se estabelece entre os coproprietários do

\footnotetext{
41 “[...] (est) produite par le concours d'un travail et d'un capital, et donc apartient au capitaliste et aux travailleurs de se distribuer les valeurs, selon les principes qui ne sauraient rien avoir de fix”. Halévy faz alusão à obra de Böhm-Bawerk (1957). Ver também Menger (1935, p. 546) e Stigler (1961).

42 Às observações de Halévy em relação aos neomarginalistas respondeu um adepto francês das teses neoliberais. Ver C. Rist (1907, p. 605 e ss.), em particular, a carta de Rist a Halévy, citada por Frobet (2003, pp. 82-3). Em defesa dos neomarginalistas, e contra toda "desvalorização do individual", lançara-se também Vilfredo Pareto, numa intervenção em 1904 durante o Congresso Internacional de Filosofia de Genebra (Pareto, 1984, pp.259-65). Halévy respondeu a Pareto afirmando que, no indivíduo, não há um "resíduo" irredutível à psicologia individual, mas uma propensão ética que o impulsiona a perseguir obstinadamente a justiça social (Halévy, 1904, pp. 1107-1113).
} 
capital social poderia permitir superar, seja a ideologia do laissez faire, seja a estratégia coletivista, baseada na expropriação e na estatização das indústrias privadas. $O$ princípio da distribuição das rendas de acordo com a necessidade poderia, então, intervir como um critério alternativo e integrar o princípio de distribuição das riquezas, baseado na ideia da troca como lei natural, a fim de abolir os últimos privilégios aristocratas do Antigo Regime (Halévy, 1906b, p. 111; Sorel, 1908, pp. 102-3; Alain, 1901, pp. 111-5).

De modo surpreendente, Halévy reivindica as razões da utopia:

É nesse sentido que os Utopistas de 1848 tinham razão, quando eles definiam a justiça através do princípio de igualdade dos salários, ou também através do princípio segundo o qual cada um recebe de acordo com as próprias necessidades [...]; ou seja, eles tinham razão de ver naquele princípio a definição de um limite ideal para o qual tende a sociedade econômica, considerada um grupo de indivíduos que abdica voluntariamente da liberdade individual, a fim de explorar em comum o capital social e de satisfazer as necessidades de todos (Halévy, 1906a, p. 591) ${ }^{43}$.

Somente a sociedade que exerce um controle, concordado democraticamente entre as partes sociais sobre a distribuição das riquezas, alcança o equilíbrio correto entre critério da necessidade e concorrência:

\footnotetext{
43 "C'est en ce sens che les utopistes de 1848 avaient raison, quand ils définissaient la justice par le principe de l'égalité des salaires, ou par le principe suivant le quel chacun reçoit selon ses besoins [...]; ils avaient raison de voir dans le principe la définition de la limite idéale, vers laquelle tend la société économique, considerée comme un groupement volontaire d'individus qui abdiquent leur liberté individuelle afin d'exploiter en commun le fonds social, et de satisfaire aux besoins de tous".
} 
[...] encontrar-se-á a conciliação entre dois princípios de distribuição da riqueza, na qual cada um receberá de acordo com a própria necessidade normal e, além disso, de acordo com o próprio trabalho: descobrirse-á então, sem dúvida, a fórmula do equilíbrio social e se estabelecerá a verdadeira democracia industrial. É preciso evitar, em todo caso, colocar o problema como ele é muitas vezes colocado hoje em dia, como uma antítese entre a liberdade e o socialismo (assim como se fazia há quarenta ou cinquenta anos, entre liberdade e democracia) (Halévy, 1906a, p. 592) ${ }^{44}$.

A conclusão parece surpreendente, lapidar: "A liberdade universal é a democracia; e há apenas uma palavra para designar a democracia universalizada e estendida do campo político ao econômico: socialismo" (Halévy, 1906a, p. 592) ${ }^{45}$.

\section{MICHELE BATTINI}

é professor de história moderna europeia e de pensamento político da Universidade de Pisa.

\section{Referências bibliográficas}

ADLER, G. 1878. Die Grundlagen der Karl Marxschen Kritik der besthenden Volkswirtschaft: Kritische und ökonomisch-literarische Studien. Tübingen: H. Laupp.

ALAIN. 1901. "Le culte de la Raison comme fondement de la république". Revue de Métaphisique et de Morale, ano 9, pp.111-8.

\footnotetext{
44 " [...] la conciliation des deux principes de la distribution de la richesse sera trouvé, ou chacun recevrait selon son besoin normal et, en outre, selon son travail; on aurait découvert alors, sans doute, la formule de l'équilibre social, et la démocratie industrielle serait fondée. [...] Il faut éviter, en tout cas, de poser le problème comme il est trop souvent posé aujourd'hui, et établir une sorte d'antithèse entre la liberté et le socialisme, comme on faisait il y a quarante ou cinquante ans, entre la liberté et la démocratie".

45 "La liberté universalisée, c'est la démocratie; et la démocratie universalisée, étendue du domaine politique au domaine économique, il n'y a qu'un mot pour la désigner, c'est le socialisme".
} 
ANGEL, P. 1961. Eduard Bernstein et l'évolution du socialisme allemand. Paris: Gallimard.

ARON, R. 1938. "Postface”. In: HALÉVY, É. L'ère des tyrannies: études sur le socialisme et la guerre. Paris: Gallimard. 1939. "L’ère des tyrannies, d' Élie Halévy". Revue de Métaphysique et de Morale, ano 46, supl. 4, pp. 238-307.

1948. "Préface". In: HALÉVY, É. Histoire du socialisme éuropéen: redigée

d'après des motes des cours par un groupe et d'élèves. Paris: Gallimard. 1970. "L’itinéraire intellectuel d'Élie Halévy". Bulletin de la Société Française de Philosophie, v. 66, p. 1-31.

BERNSTEIN, E. 1891. "Zur Frage des ehernen Lohngesetzes”. Neue Zeit, ano 9. 1893. "Der neueste Vernichter des Sozialismus". Neue Zeit, ano 11. 1969. Die Voraussetzungen des sozialismus und die Aufgaben der Sozialdemokratie. Hamburg: Rowohlt.

BÖHM-BAWERK, E.V. 1957. Teoria positiva del capitale. Turim: Utet.

BOURETZ, P. 1995. "Postface". In: HALÉVY, E. La formation du radicalisme philosophique. Paris, PUF, v. 2.

BRENTANO, L. 1890. Meine Polemik mit Karl Marx. Berlin: Walther \& Apolant. COLE, G. D. H. 1967. Storia del pensiero socialista. Laterza: Roma, v. 2.

D'ELIA, N. 1999. "Il modello inglese nella battaglia revisionistica di Bernstein (1890-1895)". Passato e Presente, n. 48, set.-dez..

FROBET, L. 2003. Élie Halévy: république et économie. Paris: Presses Universitaires du Septentrione.

FURET, F. 1995. "Préface”. In: HALÉVY, E. Correspondance 1891-1937. Paris: Édition du Fallois.

GUSTAFSSON, B. 1974. "Capitalismo e socialismo nel pensiero di Bernstein”. Annali della Fondazione Feltrinelli, ano 15.

HALÉVY, É. 1904. "Compte-rendu de la séance générale du 2ème Congrès International de Philosophie”. Revue de Métaphisique et de Morale, ano 12, pp. 1107-13.

. 1906a. "Les principes de la distribution de la richesse". Revue de Métaphysique et de Morale, ano 14.

1906b. "La démocratie: intervention è la suite de la communication de V. Basch". Bulletin de la Société Française de Philosophie, v. 6.

.1938. L'ère des tyrannies: études sur le socialisme et la guerre. Gallimard: Paris.

1948. Histoire du socialisme éuropéen: redigée d'après des motes des cours par un groupe et d'élèves. Paris: Gallimard.

1974. Histoire du socialisme éuropéen: redigée d'après des motes des cours par un groupe et d'élèves. Paris: Gallimard. 
HERKNER, H. 1891. Die Soziale Reform als Gebot des wirtschaftlichen Fortschritts. Leipzig: s/d.

HILFERDING, R. 1961. Il capitale finanziario. Milano: Feltrinelli.

HOBSBAWM, E. J. 1978. "Marx, Engels e il socialismo premarxiano". In: Storia del marxismo. Turim: Einaudi.

HOLZHENER. W. 1972. Karl Kautsky Werk als Weltanschauung. München: Beck. KAUTSKY, K. 1899. Bernstein und das Sozialdemokratische Programm. Stuttgart: J. H. Dietz Nachf. 1959. La questione agraria. Milano: Feltrinelli.

KORSCH, K. 1929. Die Materialistische Geschichtsauffassung, eine Auseinandersetzung mit Karl Kautsky. Berlin: J. H. Dietz Nachf.

LICHTHEIM, G. 1969. The origins of socialism. New York: Mc Lellan.

LUKÁCS, G. 1970. Storia e coscienza di classe. Turim: Einaudi.

MARX, K. 1970. "Teorie del plusvalore". Opere, v. 35.

MAUSS, M. 1928. "Préface”. In: DURKHEIM, É. Le socialisme: sa définition, ses débuts, la doctrine saint-simonienne. Paris: Alcan.

MENGER, E. 1934. Collected works. London: London School of Economics, v. 2. 1935. "Eugen von Böhm-Bawerk". In: Collected works. London: London School of Economics, v. 3.

PANACCIONE, A. 1974. "L'analisi del capitalismo in Kautsky". Annali della Fondazione Feltrinelli, ano 15.

PARETO, V. 1984. "L'individuel et le social”. In: Mythes et ideologies. Paris: Droz.

RIST, C. 1907. "Économie optimiste et économie scientifique". Revue de Métaphisique et de Morale, ano 15, n. 5, pp. 596-619.

SALVADORI, M. L. 1976. Kautsky e la rivoluzione socialista 1880-1938. Milano: Feltrinelli.

1978. "Kautsky fra ortodossia e revisionismo". In: Storia del marxismo. Turim: Einaudi, v. 2.

SOREL, G. 1908. Réflexions sur la violence. Paris: Rivière.

STEINBERG, H.J. 1971. "Friedrich Engels' revolutionäre Strategie nach dem Fall des Sozialistengesetzen”. In: PELGER, H. (org). F. Engels 18201870: Referate, Diskussionen, Dokumenten. Hannover: Verlag fur Literatur und Zeitgeschehen.

STIGLER, J-J. 1961. Production and distribution theories: the formative period. Nova York: Harcourt and Grace.

VENTURI, F. 1962. "Le mot "socialiste". II Congrès International d'Histoire Économique, Aix 196. Den Haag, v. 2.

WIESER, F. 1889. Der Natürliche Wert. Wien: Holder.

WOLF, J. 1892. Sozialismus und Kapitalische Gesellschaftsordnung: Kritische Würdigung beider als Grundlegung einer Sozialpolitik. Stuttgart: s/d. 


\section{DEMOCRACIA E SOCIEDADE DE MERCADO: TEXTOS INÉDITOS DE ÉLIE HALÉVY}

\section{MICHELLE BATTINI}

Resumo: $\mathrm{O}$ artigo apresenta os resultados da pesquisa realizada nos arquivos do historiador Élie Halévy, um dos maiores do século XX. Cotejando versões dos arquivos com edições póstumas, descobre-se que no debate do entreguerras, o autor da Ère des tyrannies e da Histoire du socialisme éuropée assumia, em seus últimos documentos e conferencias, que a radicalização da democracia possuía um horizonte surpreendente.

Palavras-chave: Tirania; Democracia; Liberdade Universal; Utopia; Socialismo.

\section{DEMOCRACY AND SOCIETY MARKET: ÉLIE HALÉVY'S UNPUBLISHED TEXTS}

Abstract: The article presents the results of a research conducted in the archives of the historian Élie Halevy, one of the greatest of the 20th century. Comparing versions of files with posthumous editions, one finds that in the interwar debate, the author of Ère des tyrannies and Histoire du socialisme éuropée took on in his later papers and conferences, that the radicalization of democracy had an amazing skyline.

Keywords: Tyranny, Democracy, Universal Freedom; Utopia; Socialism. 